\title{
Tambores de mortos? Sobre um estudo etnográfico da democracia em Ihéus, a antropologia feita em casa e a falácia do apelo à crença
}

\section{Filipe Verde}

\section{(2) OpenEdition \\ Journals}

Edição electrónica

URL: http://journals.openedition.org/aa/853

DOI: $10.4000 /$ aa. 853

ISSN: 2357-738X

Editora

Programa de Pós-Graduação em Antropologia Social (UnB)

Edição impressa

Data de publição: 1 junho 2010

Paginação: 265-277

ISSN: 0102-4302

\section{Refêrencia eletrónica}

Filipe Verde, «Tambores de mortos? Sobre um estudo etnográfico da democracia em Ihéus, a antropologia feita em casa e a falácia do apelo à crença», Anuário Antropológico [Online], v.35 n.1 | 2010, posto online no dia 13 outubro 2015, consultado o 28 abril 2021. URL: http:// journals.openedition.org/aa/853 ; DOl: https://doi.org/10.4000/aa.853

\section{(c) (i) (9)}

Anuário Antropológico is licensed under a Creative Commons Atribuição-Uso Não-Comercial-Proibição de realização de Obras Derivadas 4.0 International. 


\title{
Tambores de mortos? Sobre um estudo etnográfico da democracia em Ihéus, a antropologia feita em casa e a falácia do apelo à crença
}

\author{
Filipe Verde \\ Departamento de Antropologia \\ Instituto Universitário de Lisboa/ISCTE
}

\begin{abstract}
Nunca ninguém conseguiu explicar como é que trinta e nove seguidores do culto Heaven's Gate chegaram a acreditar que se se matassem em simultâneo haveriam de alcançar outra vida a bordo de uma nave espacial escondida atrás do cometa Hale-Bopp.
\end{abstract}

Evan Hughes

Relativismo é a teoria segundo a qual a verdade (ou a falsidade) de qualquer proposição é sempre relativa a certos tipos de atitudes psicológicas daquele que afirma, crê ou julga sobre a verdade da proposição.

John Searle

Comecemos por um conjunto de lugares comuns. A antropologia tem a sua razão de ser na constatação da diferença cultural e do obstáculo compreensivo que esta implica. Em função desta constatação, ela nasce de um duplo gesto - por um lado, da assunção do relativismo cultural, pré-condição da curiosidade sobre o diferente, que corre de outra forma o risco de ser simplesmente indiferente; por outro lado, pela procura de ser ciência, conjunto de princípios e regras de observação, análise e julgamento que, usando uma metáfora visual, tem por virtude tornar o opaco transparente, superar de uma forma objetiva e impessoal o obstáculo da diferença cultural. Onde viajantes, missionários ou outros (“amadores”) se haviam apenas cruzado com os mundos exóticos e haviam fracassado, o antropólogo ("profissional", "cientista") tinha um encontro e triunfava. E triunfou de fato. A disciplina adquiriu um lugar nos quadros do saber e da curiosidade científica e humanística, deram-se a conhecer realidades sociais e culturais, mundos humanos que, de outra forma, teriam permanecido por conhecer, o relativismo moral adquiriu uma legitimidade de tons científicos e, portanto, aparentemente não-ideológica, a sua forma especial de olhar para fora influenciou por vezes de maneira significativa a forma como olhamos para dentro, para questões como a raça, a adolescência, a 
sexualidade, a religião ou o poder.

Os títulos dos livros que constituíram os primeiros clássicos da disciplina estavam repletos de palavras como "selvagem", "primitivo" e "arcaico" - A Vida Sexual dos Selvagens, Estrutura e Função na Sociedade Primitiva, Ensaio sobre a Dádiva: Forma e Razão da Troca nas Sociedades Arcaicas - mas a seu tempo estes termos tornaram-se incômodos, sem que nunca se tenha encontrado um eufemismo adequado para substituí-los, a não ser o muito abstrato e aparentemente neutral "outro" - outros mundos, outras culturas, formas de pensar outras, o Outro. Para chegar a ele, o antropólogo cruzava oceanos, montanhas e vales, instalava-se numa qualquer aldeia perdida e isolada e aceitava com presciência relativista o fato de a sua presença ser tornada pelos nativos uma não-presença - um sujeito que não pertence ali, que ninguém compreende muito bem o que quer ou anda fazendo, de quem ninguém espera nada e que, consequentemente, não deve ele próprio esperar nada por parte de ninguém.

Agora já não é assim. Os índios brasileiros usam o vídeo como instrumento de ação política, os índios da Califórnia e da Flórida prosperam com o jogo, legal nas reservas, o antropólogo que se decida a viajar para as ilhas Trobriand ou para Samoa pode assistir aos jogos do seu país no mundial de futebol no bar da aldeia. Além disso, se nas primeiras décadas do século XX havia mais sociedades "selvagens" e "primitivas" do que antropólogos, muito rapidamente passou a haver mais antropólogos que mundos que merecessem ser adjetivados como tal, os primeiros em número preocupantemente crescente, os segundos em número tragicamente decrescente.

Esquecidos os selvagens, encontraram-se os camponeses, em versão mediterrânica, andina ou oriental, e depois outros que pudessem ser ainda outros. E hoje já não há limites para o que pode ser outro: o karaokê em Lhasa, os shows gays de televisão em Porto Rico, as gangs de Los Angeles, ou Wall Street. Mas, sem dúvida, o que caracteriza estas mudanças é o fato de já não se ir num sentido autêntico para fora, de o antropólogo agora permanecer "em casa".

Dir-se-ia, reconhecidos os lugares comuns acima enunciados, que algo se perdeu: a própria antropologia, essa ciência que aprendia porque olhava para fora, que dava uma atmosfera nova à forma de olhar para dentro. Mas talvez, como dizem alguns, a antropologia seja apenas o que os antropólogos fazem. Havendo como há muitos antropólogos, e continuando como continuam a fazer trabalho de campo e a escrever, deve portanto continuar a haver antropologia. É disso que estamos aqui à procura, céticos quanto ao que encontramos.

Tomamos como referente dessa busca crítica um, e apenas um, exemplo de conversão do enfoque do olhar antropológico do distante para o próximo - um estudo "etnográfico da democracia", empreendido a partir de um trabalho de cam- 
po em Ilhéus por um antropólogo brasileiro, M. Goldman. ${ }^{1}$ Seguimos assim um preceito caro à tradição da disciplina, sempre em busca de discutir "big issues" por relação ao que é dado a observar em "small places", em pensar, como Malinowski, a natureza humana a partir do mundo de uma aldeia, em não desconsiderar e saber valorizar, como dizia Mauss, as repercussões gerais do estudo intensivo de um caso particular, em - por que não? - discutir a disciplina no seu estado atual a partir de um dos seus exercícios etnográficos contemporâneos, aliás, explicitamente interessado em discutir o significado, as condições e as possibilidades de "manter o ponto de vista antropológico tradicional quando o objeto observado faz parte do coração da sociedade do observador" (Goldman 2003:445).

\section{$* * *$}

O movimento que trouxe a antropologia para casa foi também aquele em que ao relativismo cultural fundador se juntaram doses cada vez maiores de relativismo epistemológico e, sem dúvida, "repatriamento" e relativização se alimentaram reciprocamente. Afinal, ficar próximo é permanecer no que já se conhece, o que se conhece é o que se compreende, e o que se compreende é o que não exige o recurso a uma mediação metodológica - como sempre o soube Weber. Não foi no entanto por influência de Weber, que sempre perseguiu um ideal de objectividade e laboriosamente construiu uma das teorizações clássicas da sociologia, que a antropologia caiu no relativismo epistemológico. Este é muito mais a manifestação de um ambiente geral que foi invadindo e tomando importância cada vez maior nas ciências humanas do que um processo endógeno da disciplina. Além disso, os antropólogos não viram o seu "repatriamento" como se implicasse uma mudança qualitativa das realidades por si estudadas.

É certo que nesses tempos de “compenetração mútua” já não se estudam, como diz Lévi-Strauss, "testemunhos de crenças, de formações sociais, de instituições nascidas em completo isolamento em relação às nossas, e que constituíam, assim, contribuições insubstituíveis ao patrimônio da humanidade” (Lévi-Strauss \& Mortaigne, 2005), mas o ambiente cosmopolita das cidades e dos países que os antropólogos conhecem e onde vivem corresponde a locais onde se cruzam um número dir-se-ia infindável de diferenças culturais e, além disso, a sua aprendizagem habilitou-os a criar um distanciamento em face do que é próximo. Onde antes a diferença cultural era um dado, agora ela é construção, onde antes se interrogava o que era exótico para torná-lo familiar, agora se olha o familiar de forma a torná-lo exótico. A marca da antropologia já não é a distância, mas o olhar distanciado, e este já não é um olhar dirigido por "grandes narrativas" (teorias científicas da cul- 
tura ou da sociedade), mas sim e meramente, na melhor das hipóteses, por "médias narrativas" ou, na pior, pela particularidade da experiência de distanciamento e, supomos, na sofisticação das formas como o antropólogo é capaz de explorá-la. Neste passo, o ideal da impessoalidade deu lugar à subjetividade, e esta transformou o eu do antropólogo no âmago da antropologia, que assim se tornou, segundo Geertz, "hipocondríaca".

A pedra de toque da análise de Goldman da ação e da intervenção dos blocos afro e terreiros na política local de Ilhéus é uma redefinição do modelo segmentar, que começou por fazer história na antropologia através das monografias africanistas dos funcionalistas britânicos de segunda geração, uma redefinição que é feita por recurso às ideias de Deleuze e Guattari sobre a natureza plural do que se deve entender por "segmentação" (Deleuze e Guattari são autores omnipresentes em toda a obra). Não nos cabe aqui perseguir os detalhes que todo leitor nela poderá encontrar claramente expressos. Seguindo o autor, o essencial consiste no que chama "desnueizar" o modelo segmentar, desligando-o de dois vícios de raiz que consistiriam na sua "morfologização" e "tipologização", o primeiro termo indicando a sua identificação com um tipo específico de organização social, o segundo, a tendência a vê-lo como um modelo intermediário de organização política entre sociedades sem Estado, organizadas politicamente por referência ao parentesco, e as sociedades com Estado, assentes sobre um princípio territorial.

Goldman pretende generalizar e dar uma dimensão "processual” ao conceito de segmentaridade sob a hipótese de que ele é um princípio heurístico passível de ser produtivamente transportado para fora dos seus domínios habituais. Para isso distingue com Deleuze e Guattari entre formas "arborescentes" e "rizomáticas" do princípio segmentar que, além disso, seria enquadrável em três "modalidades": "binárias", "circulares" e "lineares" (ibid.:141-146). A mais valia de tal reelaboração teórica do modelo segmentar e da sua combinação com uma estratégia etnográfica, tal como Goldman a define, seria a possibilidade de pensar a ação dos agentes dos blocos afro e terreiros em termos que, por um lado, evitariam olhar para essa realidade nos termos clássicos e alternativos entre si do "substantivismo" e do "formalismo" e, por outro, contornar a tendência (apresentada tão só assim e como uma espécie de inevitabilidade) de as "teorias sobre o poder se transformarem em teorias de poder" (ibid.:42).

Cabe aos especialistas do contexto etnográfico e nacional das questões políticas em questão que não se perderem na teia em que se converte a outrora simpaticamente simples "segmentaridade", julgarem sobre a valia ou a utilidade de tal construção para pensar concreta e esclarecidamente as ideias e a ação política dos blocos de que o livro nos fala. O que nos interessa aqui é algo que está aquém destas 
questões e do segmentarês abstratizante que as alimenta.

Logo na primeira página de Como Funciona a Democracia, Goldman narra uma experiência de terreno por si vivida e que, a partir de certo momento da sua pesquisa e escrita, compreendeu ser importante o suficiente para que lhe desse um lugar central no argumento do livro. Como descreve no Prólogo ("Os tambores dos mortos e os tambores dos vivos"), foi-lhe a certo momento pedido que utilizasse o seu carro para levar e depositar no rio uma caixa onde se encontravam os objetos de culto de uma mãe-de-santo que havia morrido recentemente. Quando a caixa foi atirada ao rio, o antropólogo se deu conta de que as duas mulheres que o acompanham estavam em transe e ouviram-se tambores ao longe. Fim do episódio. Alguns dias depois, de forma fortuita, numa conversa com um dos seus amigos e informantes, soube que o som dos tambores naquele momento era o sinal de que os mortos recebiam com satisfação a alma da morta e, ponto significativo, que os tambores eram tambores dos mortos.

Ter percebido "que os tambores que ouvira simplesmente não eram tambores de vivos" (Goldman, 2006b:15) teve o impacto suficiente para que o relatasse mais tarde a duas colegas de profissão, uma das quais o relembrou de que ele mesmo orientara a tempos uma dissertação em que tais fatos eram "amplamente descritos e analisados", revelando assim uma "amnésia” da sua parte. A outra colega comentou o caso dizendo que ele “'estava realmente fazendo trabalho de campo' e que as pessoas do terreiro e ele escutavam os tambores pelas mesmas razões” (ibid). Dois anos mais tarde, Goldman recebe uma mãe-de-santo de Ilhéus em S. Paulo e, em encontros repetidos, é acometido de vertigens que desaparecem assim que os encontros terminam. Escreve então a um colega britânico confessando a sua surpresa pela história, tanto mais que não conhecia em si mesmo "nenhuma inclinação mística".

Vale a pena seguir a resposta do britânico, P. Gow, incluída no capítulo, em que relata que no seu trabalho de campo viveu uma experiência semelhante - experiências que aparentemente são de uma espantosa frequência - só que onde Goldman escutara tambores ele escutara flautas. Mas onde Goldman esbarrava na perplexidade, ou mesmo na inquietação, Gow abre, segundo ele, as vias da "explicação fenomenológica, quase gestaltista" do fenômeno. O que se segue é uma paráfrase dessa explicação.

Em estados de elevada sensibilidade, padrões sonoros apreendidos pelos sentidos, como os da água no rio ou os de uma noite tropical, podem ser projetados no mundo sob formas potencialmente muito diversas, como flautas ou tambores, como o exemplificam as suas experiências - diz o britânico. E depois acrescenta: isso não nos acontece só a nós, acontece também com aqueles que estudamos “eles obviamente ouvem essas coisas". E isso tem ponderosas consequências. Há 
que repensar "radicalmente" o "problema" da crença. E o parâmetro para esse repensamento é logo dado: "pelo menos", devemos "deixar de dizer preguiçosamente que os 'fulanos creem que os mortos tocam tambores' ou que 'os beltranos acreditam que os espíritos tocam flautas'. Eles não 'acreditam', é verdade! É um saber sobre o mundo" (ibid.:15-16).

O que é digno de nota não é o fato de os crentes no espiritismo acreditarem como acreditam que os mortos tocam tambores e que os vivos os podem ouvir. Afinal, a capacidade de acreditar do homem não conhece limites, não havendo fantasia por mais absurda que não encontre alguém disposto a encontrar nela uma verdade, ou até, quem sabe, um guia para a sua orientação no mundo. O que é digno de nota é o fato de antropólogos academicamente instalados se disponham a "levar a sério" tal crença e a torná-la pretexto e via possível de chegar a dizer alguma coisa de útil sobre a crença, o conhecimento ou a verdade.

Tentando contornar a "hipocondria" que assaltou alguns e repondo os pés na terra de um saudável (bom) senso comum, designamos aqui por crenças as ideias que alguém considera verdadeiras independentemente, ou até contra, uma avaliação e julgamento críticos e coerentes sobre a sua plausibilidade ou justificação realista. Nesse sentido, a crença deve ser distinguida do conhecimento, que abarca as ideias que, simetricamente, consideramos como válidas ou verdadeiras em função do exercício dessa tal faculdade de escrutinar crítica e coerentemente o que as qualifica como tal. E não vale a pena soterrar a distinção entre crença e conhecimento sob nenhuma filosofia irracionalista, reconstrução relativizadora da história da ciência, ou denúncia do conhecimento como forma de poder, porque nada disso consegue obscurecer a dimensão pragmática dessa distinção - de que em última instância depende que não vivamos num mundo esquizofrênico onde a astrologia, o creacionismo, a astronomia e a biologia valham por igual.

Uma das coisas que esse senso comum permite evitar é a falácia do apelo à crença como modo de não mais distinguir entre o disparate e a verdade e de assim nos condenarmos à esterilidade cognitiva e à futilidade intelectual. Sim, é claro que os tambores e as flautas de mortos são audíveis e verdadeiros, que se trata de um "saber sobre o mundo" mas, sendo assim, porque não hão de ser também saberes sobre o mundo as crenças sobre bruxas, duendes, bolas de cristal, o vudu, milagres e extraterrestres capazes de mais ou menos "fenomenologicamente" resgatarem alguns para a imortalidadade?

Goldman está preocupado em dar à sua experiência uma "dignidade" que habitualmente não é dada às "anedotas" de experiências místicas vividas por antropólogos no terreno. Essa dignidade passa em primeiro lugar por recusar as duas explicações "mais fáceis" - a "mística" ou a "materialista”, segundo as quais os tambores são mes- 
mo de mortos (coisa interessante) ou são meramente de vivos (coisa trivial). Para Goldman, o que é significativo e se deve reter é o fato de o "evento o ter atingido em cheio", de "ter levado a história a sério". Encontra um eco de tal situação nos trabalhos de Favret-Saada sobre a feitiçaria em França, em que esta discorre sobre as "comunicações involuntárias" vividas por vezes por antropólogos no terreno e sobre a "necessidade da aceitação de ser afetado pela experiência indígena", uma afetação que não implica porém nem a identificação empática com o ponto de vista nativo (que, supomos, os levaria a aceitar a explicação mística), nem a assunção de algum tipo de privilégio e distanciamento epistemológico (em nome do qual, é lícito pensar, os antropólogos da velha guarda aceitariam a explicação materialista).

Segundo Goldman, a etnografia não é um mero exercício de observação, ou tão pouco uma forma de assunção do ponto de vista do outro, e ainda menos pode resultar numa "transformação substancial" nesse outro, e a melhor forma de defini-la seria por recurso à noção de Deleuze e Guattari de "devir", relativa a uma “economia do desejo". Se a etnografia não é observação, assunção do outro olhar ou transformação no outro, o devir não é "semelhança, imitação ou transformação”, é outra coisa: “é o movimento através do qual um sujeito sai de sua própria condição por meio de uma relação de afectos que consegue estabelecer com uma condição outra” - em que “'afecto’ não tem, absolutamente, o sentido de emoções ou sentimentos mas de 'afecções' [...] que compõem, decompõem ou modificam um indivíduo" (ibid.:31).

Está assim aberta a possibilidade de dar dignidade e um estatuto epistemológico aos tambores dos mortos, às amnésias e às vertigens que o etnógrafo sente em presença de uma mãe-de-santo. Eles fazem parte do "devir nativo", das experiências não intencionais, e não enquadráveis como "crença” que transformam aquele que as atravessa. Não surpreende assim que o trabalho de campo intensivo seja visto por Goldman como uma "exigência da antropologia”, uma exigência que, diga-se, a torna muito, muito exclusivista. Como o atesta a comparação da etnografia enquanto "processo" com a chamada "análise didática" dos psicanalistas, o conhecimento antropológico assim compreendido só é acessível em última instância àqueles que viveram a experiência do trabalho de campo, dado que esta é a "condição para a justa compreensão até mesmo de outras experiências de campo” (ibid.:30). É preciso portanto ouvir os tambores dos mortos para saber que os mortos os tocam - e tambores, flautas ou orquestras inteiras de mortos confesso que nunca os escutei, como não os devem ter escutado, parece lícito afirmá-lo, a maioria dos etnógrafos.

Segundo E. Wolf (2001:50), "a antropologia definiu-se como a disciplina que tentou encontrar boas razões para o comportamento absurdo". Wolf tem certamente em mente todos os textos, alguns muito famosos e continuamente evoca- 
dos nas discussões sobre o conhecimento antropológico, em que antropólogos e filósofos procuram, encontrando essas "boas razões", demonstrar que as crenças e as práticas comumente denominadas de absurdas ou irracionais são afinal, se consideradas no seu contexto próprio, apenas "aparentemente" tal - uma ilustração da finalidade fundamental da adoção do relativismo cultural. A premissa subjacente era a de que as crenças presentes nas sociedades "primitivas" apresentavam uma defasagem essencial em relação às do próprio antropólogo. Afinal, este representa uma tradição que remonta e se desenvolveu em relação às obras de autores como Platão, Newton, Kant e Darwin, uma tradição que seria aliás o fundamento da superioridade do conhecimento antropológico em comparação com o dos amadores, não orientado por teorias e metodologias científicas ou, pelo menos e talvez mais realisticamente no caso das chamadas ciências humanas, de intenção científica.

Assim como no ambiente da cosmologia cristã e antes de se conhecer a primeira lei de Newton se considerava que o movimento de um objeto era dependente do exercício de uma força sobre ele, e havia portanto "boas razões" para pensar que os planetas eram empurrados por anjos, não seria uma surpresa descobrir que nos mundos estudados pelos antropólogos fossem plausíveis e correntes crenças do mesmo tipo, alicerçadas em premissas "sobrenaturais" e não-naturalistas. O sentido de abandonar o confor to de casa e cruzar oceanos, montanhas e vales era precisamente o de ir ao encontro desses mundos onde se pensava e se acreditava nessas coisas para descobrir as suas "boas razões" que, uma vez trazidas à luz, permitiam, segundo Wolf, "alargar o sentido do que é ser humano".

O livro de Goldman, uma reflexão sobre as condições e as estratégias da antropologia que se faz em casa, é assim uma ilustração perfeita de que a antropologia pode de fato ficar em casa, embora por razões diferentes das que o seu autor tem em mente. É que onde antes se atravessavam oceanos para encontrar ideias absurdas e, mais do que isso, a crença nelas, agora podemos encontrá-las aqui mesmo ao nosso lado, dado que na academia há colegas que ouvem música de mortos, "levam isso a sério" e, além do mais, encontram nessa experiência "mística" o motto da sua concepção de antropologia e de conhecimento antropológico, ou pelo menos do conhecimento antropológico dos contextos em que tais músicas se fazem ouvir...

Goldman quer fazer uma "abordagem verdadeiramente antropológica da política” e, para isso, socorre-se de uma "teoria”, uma “teoria etnográfica”. Esta deve ser entendida como uma "grade de inteligibilidade" pela qual os "elementos concretos do trabalho se articulam em proposições um pouco mais abstratas", algo que tem 
por objetivo "elaborar um modelo de compreensão de um objeto social qualquer (linguagem, magia, política) que, mesmo produzido em e para um contexto particular, seja capaz de funcionar como matriz de inteligibilidade em outros contextos" (ibid.:28). Uma teoria deste tipo, que já estaria presente em Malinowski, coloca a antropologia no "soberbo ponto de mediação, o centro, não o centro ponto pusilânime que detesta os extremos, mas o centro sólido que sustenta dois extremos num notável equilíbrio" (Kundera). O equilíbrio entre o quê? Encontramos o catálogo das antinomias teóricas e dos preceitos politicamente corretos da antropologia: entre o "subjetivismo" e o "objetivismo", entre a "parcialidade" e a "arrogância", entre o "concreto" e o "mais abstrato", entre a particularidade do "ponto de vista nativo" e a inteligibilidade "mais global" que o antropólogo procura alcançar, entre o que é "marginal aos centros de poder" e o que os "estrutura". A procura desse "notável equilíbrio" (que, supomos, cria ou pelo menos não impede a possibilidade das “afetações" e das experiências de "devir" do etnógrafo) é naturalmente motivada pela assunção, dir-se-ia inevitável na antropologia, do relativismo cultural - da "decisão a priori de conferir a todas as histórias que escutamos o mesmo valor" (ibid.:25) e de "suspender os juízos de valor".

Nesse sentido, o seu estudo etnográfico da política tem por objetivo "produzir uma perspectiva sobre o nosso próprio sistema político equivalente àquela elaborada, por exemplo, por Evans-Pritchard para os Nuer, analisando assim a democracia como parte dos 'Western Political Systems'” (ibid.:33) - uma ideia que Goldman relata ter defendido num encontro científico nos primeiros passos da sua pesquisa. Uma sua interlocutora levantou, no entanto, uma objeção cuja relevância não escapou a Goldman. É que o trazer do olhar relativista para o estudo da sociedade de que o próprio antropólogo faz parte incorre no risco "ético e político" de esvaziar de legitimidade os seus próprios valores - nomeadamente aqueles que o fazem defensor da democracia. "Não recordo muito bem o que respondi na ocasião, mas me lembro de um certo espanto ao me defrontar com uma objeção que, no limite, significaria um obstáculo quase intransponível para a análise antropológica da nossa própria sociedade" (Goldman, 2000, itálicos meus). Goldman descobre assim que é "bem mais fácil ser relativista entre os Azande do que entre nós".

O princípio relativista tem, portanto, consequências indesejáveis e que têm a ver com o seu uso dúplice e seletivo quando se considera à sua luz essas coisas diferentes que são o antropólogo e o "outro", exótico ou exotizado. Servindo quando virado para fora para demonstrar a forma própria de legitimidade e a natureza verdadeira (mas relativa) das ideias e das crenças dos outros que o nosso equipamento cultural nos torna céticos, o relativismo cultural, quando virado para dentro, mostra também que as nossas próprias ideias e valores não emanam de uma ordem natural 
do mundo ou do pensamento e não são legítimas a priori, antes meras convenções passíveis de uma crítica de que pode resultar uma mais lúcida visão de nós mesmos e dos elementos que fazem a nossa identidade - é assim desde Heródoto e, quando não há efetivamente um outro que sirva de contraponto a nós, é sempre possível inventá-lo de raiz, como Montesquieu nas Cartas Persas.

O problema é que a antropologia, conservadora quando olha para fora e crítica quando olha para dentro, permanece assim presa a um double bind, que por vezes faz ricochete e atinge alvos indesejados. Sendo fácil e inócuo justificar a feitiçaria Azande, ou até ouvir tambores de mortos, é difícil, como vimos, e talvez mesmo um risco "ético e político", justificar o "desprezo" dos membros dos blocos pelos valores políticos da democracia de que o antropólogo é defensor - numa inversão dos papéis respectivos tradicionais do antropólogo e do nativo, como nota Goldman, visto que é o primeiro que se define como crente e o segundo, como cético... O "centro sólido" que a "teoria” permite encontrar não supera, portanto, o contraste entre a crença do antropólogo na democracia e o desprezo do nativo por ela - a não ser que por meio de alguma "comunicação involuntária" ou "afecção" deleuziana o primeiro tome também como seu esse desprezo.

As afecções a que o antropólogo feito etnógrafo em "devir” está sujeito não são no entanto significativas o suficiente para que esse resultado se produza. Felizmente, diríamos, porque, invertendo nestes tempos seculares a frase de Hume, os erros em religião são meramente ridículos, enquanto os erros filosóficos (e também, acrescentamos, os políticos) podem ser, de fato, perigosos. Capaz de ouvir tambores de mortos e de ser por eles afetado, não há experiência de terreno ou momentos de "particular sensibilidade" que o demovam dos valores políticos que o fazem defensor da democracia. O problema é que esses valores passam, e em alguma medida definem-se mesmo, pelo relativismo cultural, no qual, "com espanto", o antropólogo encontra um "obstáculo quase intransponível para a análise antropológica da nossa própria sociedade”, um obstáculo que implica, pelo menos no que toca às suas ideias políticas, que o relativismo seja colocado entre parênteses ou mesmo simplesmente posto de parte.

O que Goldman parece inadvertidamente descobrir é que só se é relativista em relação ao que se considera "verdade", mas nunca ao que se considera, agora sem aspas, verdade - mas perceber isto exige, pelo menos, que nunca se confundam crença e conhecimento. Como disse Gellner (1995:33, itálicos meus), "seja o que for que os antropólogos possam dizer quando falam das suas práticas fora das horas de expediente, eles, quando realmente trabalham, não são nem podem ser relativistas" - nem epistemologicamente relativistas (era este o sentido visado por Gellner), nem culturalmente ou politicamente relativistas. Como diz Herzfeld (2001:31), 
e o ilustra involuntariamente Goldman, "o relativismo cultural, se queremos que tenha alguma espécie de sentido, tem de ser situado numa visão pragmática”.

Goldman não quer, vimo-lo, que o episódio dos tambores dos mortos e as “comunicações involuntárias” e as “afecções” tenham valor anedótico. Quer, pelo contrário conferir-lhes dignidade - o que, parece lícito pensar, passa por mostrar que eles estão de alguma maneira relacionados, ou são mesmo a condição de alcançar "um conhecimento verdadeiramente antropológico da democracia" (itálico meu). Goldman está consciente de que as suas experiências e as crenças referentes aos tambores não têm uma relação imediata com as questões por ele estudadas. Segundo ele, foi só ao fim de três anos que conseguiu estabelecer a "ponte" entre as duas coisas, por intermédio de um sonho que reproduziu fielmente a sua memória de algo que acontecera "três dias antes dos tambores" - uma conversa com um político local do Partido dos Trabalhadores, em que se ouviam tambores ao longe (desta vez de vivos) e em que este havia sugerido que as batucadas eram sinal de indolência e irresponsabilidade cívica.

O clic que permite a Goldman ligar os tambores dos mortos com a sua pesquisa sobre política, chegar a um conhecimento verdadeiramente antropológico desta, é a percepção de que à luz das concepções do seu interlocutor os tocadores vivos de tambores são afinal "seres apenas semivivos (já que alienados)" (2006b:18). A ponte estabelece-se por via de um desacordo do antropólogo em relação à ideia defendida pelo político, afinal, a sua longa convivência com os membros dos blocos afro o havia ensinado a admirar as suas performances musicais e a compreender quanto elas são "uma das dimensões essenciais dos processos de criação de territórios existenciais que permitem a pessoas discriminadas produzirem a sua própria dignidade e vontade de viver" (ibid.).

Semivivos porque alienados? Porque mais ou menos alienados, mais ou menos vivos do que o político do Partido dos Trabalhadores que fez o comentário sobre as batucadas ou que o próprio antropólogo? Onde é que está o relativismo e a recusa da arrogância quando este reserva para si a decisão de decretar, em nome da exclusivista vivência etnográfica, que os nativos têm a sua "própria dignidade"? - não deveria esse mesmo relativismo, pelos seus a priori, ser à partida concomitante ao reconhecimento de que a dignidade não tem nada a ver com discriminação, ou só é digno quem o antropólogo escolhe identificar primordialmente como discriminado? Da mesma forma que não precisamos ouvir e crer em tambores de mortos para poder inquirir, à luz de um desígnio de imparcialidade e verdade, modos de pensar, ideias e crenças outras (seja sobre "a linguagem, a magia ou a política”) mesmo que deles tenhamos de discordar - também não precisamos ouvir os tambores de vivos para saber que esta arte admirável está associada, como outras artes 
para outros (quem sabe em que aspectos também eles talvez discriminados - drag queens, toureiros ou antropólogos, por exemplo) à criação de "territórios existenciais".

Os equívocos a partir dos quais Goldman ergue a sua concepção de antropologia são afinal os equívocos de qualquer antropologia (caseira ou exótica, "centrípeta" ou "centrífuga", nos termos de Geertz) que não seja capaz de situar o relativismo cultural na "visão pragmática" de que fala Herzfeld. Não ser capaz de fazer isto o faz cair, por um lado, no erro de radicalizar e tornar as suas experiências psicológicas e o apelo à crença (que parecem ser os sintomas da hipocondria atual de muita antropologia) em critérios de demarcação dos limites do plausível e do inverosímil, ou melhor, como álibi para evitar essa demarcação - e de assim acreditar no incrível, ou pelo menos levá-lo "a sério"; e o faz, por outro lado, encontrar os limites desse mesmo relativismo, que quando confronta os seus valores políticos torna o empreendimento por ele conduzido perigoso, e que tem nesse passo de ser abandonado.

Entre uma assimilação acrítica das ideias "místicas" dos seus "nativos” e uma tolerância impossível das suas ideias políticas, o "devir" místico de Goldman não parece encontrar motivos para ponderar criticamente os custos do relativismo (pedir isto a um antropólogo parece muitas vezes algo semelhante a pedir a um crente que renuncie aos dogmas que sustentam a sua fé), nem os limites do empreendimento assim guiado, por muito que a experiência de terreno o tenha habilitado a ouvir tambores de mortos. É que parece simplesmente inconcebível conjecturar os resultados que as "comunicações involuntárias" e as "afecções" sofridas pelo antropólogo poderiam ter se ele tivesse, por exemplo, estudado o Heaven's Gate Cult - não fosse ele descartar, contra si próprio, a favor de si próprio, a sua confiança, afinal não tão cega assim, nas virtudes (morais certamente, mas nem sempre, epistemológicas, arriscaríamos dizer, quase nulas) do relativismo cultural.

\section{Notas}

1 Como Funciona a Democracia: uma teoria etnográfica da política (2006) é o resultado final da pesquisa de Goldman. Previamente, o seu autor publicou partes significativas do que viria a ser essa obra sob a forma de artigos em várias revistas de antropologia. É esse conjunto de textos que tomamos por referente. 


\section{Referências bibliográficas}

GELLNER, Ernest. 1997. Antropologia e Política: revoluções no bosque sagrado. Rio de Janeiro: Jorge Zahar Editor.

GOLDMAN, Marcio. 2000. "Uma Teoria Etnográfica da Democracia: a política do ponto de vista do movimento negro de Ilhéus, Bahia, Brasil”. Etnográfica, vol. 4, n. 2.

. 2003. "Os Tambores dos Mortos e os Tambores dos Vivos. Etnografia, Antropologia e Política em Ilhéus, Bahia”. Revista de Antropológia, vol. 46, n. 2, São Paulo, USP.

. 2006. "Alteridade e experiência: antropologia e teoria etnográfica”. Etnográfica, vol. 10, n. 1.

. 2006b. Como Funciona a Democracia. Uma teoria etnográfica da política.

Rio de Janeiro: 7Letras.

HERZFELD, Michael. 2001. Anthropology - Theoretical Practice in Culture and Society. Oxford: Blackwell Publishing.

LÉVI-STRAUSS, Claude \& MORTAIGNE, Véronique. 2005. Loin do Brésil. Paris: Chandeigne.

WOLF, Eric. 2001. "Fieldwork and Theory". In: Pathways of Power - building an anthropology of modern world. Berkeley: University of California Press. 